University of Nebraska - Lincoln

DigitalCommons@University of Nebraska - Lincoln

\title{
Scale-invariant stress orientations and seismicity rates near the San Andreas Fault
}

Amy Day-Lewis

Stanford University

Mark D. Zoback

Stanford University, zoback@stanford.edu

Stephen Hickman

U.S. Geological Survey

Follow this and additional works at: https://digitalcommons.unl.edu/usgsstaffpub

Part of the Earth Sciences Commons

Day-Lewis, Amy; Zoback, Mark D.; and Hickman, Stephen, "Scale-invariant stress orientations and seismicity rates near the San Andreas Fault" (2010). USGS Staff -- Published Research. 401.

https://digitalcommons.unl.edu/usgsstaffpub/401

This Article is brought to you for free and open access by the US Geological Survey at DigitalCommons@University of Nebraska - Lincoln. It has been accepted for inclusion in USGS Staff -- Published Research by an authorized administrator of DigitalCommons@University of Nebraska - Lincoln. 


\title{
Scale-invariant stress orientations and seismicity rates near the San Andreas Fault
}

\author{
Amy Day-Lewis, ${ }^{1}$ Mark Zoback, ${ }^{1}$ and Stephen Hickman ${ }^{2}$ \\ Received 6 August 2010; revised 24 October 2010; accepted 28 October 2010; published 21 December 2010.
}

[1] We analyzed measurements of the direction of maximum horizontal compressive stress as a function of depth in two scientific research wells near the San Andreas Fault in central and southern California. We found that the stress orientations exhibit scale-invariant fluctuations over intervals from tens of $\mathrm{cm}$ to several $\mathrm{km}$. Similarity between the scaling of the stress orientation fluctuations and the scaling of earthquake frequency with fault size suggests that these fluctuations are controlled by stress perturbations caused by slip on faults of various sizes in the critically-stressed crust adjacent to the fault. The apparent difference in stress scaling parameters between the two studies wells seem to correspond to differences in the earthquake magnitudefrequency statistics for the creeping versus locked sections of the fault along which these two wells are located. This suggests that stress heterogeneity adjacent to active faults like the San Andreas may reflect variations in stresses and loading conditions along the fault. Citation: Day-Lewis, A., M. Zoback, and S. Hickman (2010), Scale-invariant stress orientations and seismicity rates near the San Andreas Fault, Geophys. Res. Lett., 37, L24304, doi:10.1029/2010GL045025.

\section{Introduction}

[2] The regional direction of the maximum horizontal compressive stress in central and southern California (Figure 1) is generally uniform and consistent with models that incorporate far-field shear stresses associated with relative Pacific-North America plate motion and buoyancy-related stresses resulting from the thermally-elevated Basin and Range province to the east [Flesch et al., 2000]. In this study we analyze significant variations in the direction of the maximum horizontal compressive stress, $\mathrm{S}_{\mathrm{Hmax}}$, with depth in two scientific research boreholes along the San Andreas: the San Andreas Fault Observatory at Depth (SAFOD) Pilot Hole, located $1.8 \mathrm{~km}$ southwest of the surface trace of the San Andreas Fault in central California, and the Cajon Pass well, located $4 \mathrm{~km}$ northeast of the fault in southern California (Figure 1). In the SAFOD Pilot Hole, wellbore failures and shear-wave velocity anisotropy reveal $\mathrm{S}_{\mathrm{Hmax}}$ orientations with multi-scale fluctuations superimposed on an overall clockwise stress rotation with depth, such that $\mathrm{S}_{\mathrm{Hmax}}$ attains an angle of $\sim 70^{\circ}$ to the San Andreas Fault at the bottom of the well [Hickman and Zoback, 2004; Boness and Zoback, 2006]. Stress orientations in the Cajon Pass well also show consid-

\footnotetext{
USA.

${ }^{1}$ Department of Geophysics, Stanford University, Stanford, California,

${ }^{2}$ U.S. Geological Survey, Menlo Park, California, USA.
}

Copyright 2010 by the American Geophysical Union. 0094-8276/10/2010GL045025 erable fluctuations with depth, with a mean $\mathrm{S}_{\mathrm{Hmax}}$ direction near the bottom of the hole that is rotated clockwise with respect to the regional trend, possibly due to slip on the nearby Cleghorn Fault [Shamir and Zoback, 1992]. The Cajon Pass data cover a depth range of 1.75 to $3.45 \mathrm{~km}$. The SAFOD Pilot Hole data cover a depth range of 0.83 to $2.15 \mathrm{~km}$. In both cases, the observations of stress orientation were made in highly fractured granitic rocks beneath the sedimentary cover.

[3] The goals of the work discussed here were to determine the nature of the multi-scale stress orientation fluctuations observed in these two wells and then examine the resulting implications for stress heterogeneity along the San Andreas and other active faults. Similar observations have been made in deep boreholes in other parts of the world [Barton and Zoback, 1994; Brudy et al., 1997], where the orientation of $\mathrm{S}_{\mathrm{H} \max }$ with depth varies at multiple scales around a consistent mean orientation.

\section{Methods}

[4] Because stress is concentrated around a cylindrical wellbore wall, compressive or tensile failure of the rock surrounding the wellbore occurs when the stress concentration exceeds the strength of the rock. In near-vertical wells, the orientation of stress-induced compressive failures (borehole breakouts) can be used to map the azimuth of $\mathrm{S}_{\mathrm{Hmax}}$ [Bell and Gough, 1979; Zoback et al., 1985]. In thousands of wells worldwide, mean $\mathrm{S}_{\mathrm{Hmax}}$ directions determined using this technique agree with independent stress indicators such as earthquake focal mechanisms and young geologic data [Zoback et al., 1989]. The continuous nature of wellbore image data permits the azimuth of $S_{H \max }$ to be determined with high depth resolution and over appreciable depth ranges. In the present study the vertical resolution is $5 \mathrm{~cm}$ in the SAFOD Pilot Hole and $4 \mathrm{~cm}$ in Cajon Pass. Stress orientations were determined from observations of borehole breakouts and drilling-induced tensile cracks in the SAFOD borehole by Hickman and Zoback [2004] and by Shamir and Zoback [1992] in the Cajon Pass borehole.

[5] Qualitatively, variations in stress azimuth in both study wells appear to have a similar character regardless of depth and scale, as illustrated in Figure 2. This behaviour suggests scale invariance, or self-similarity. For a scaleinvariant (i.e., fractal) phenomenon there are no dominant spatial frequencies, and spectral analysis will reveal a power-law relationship between the power spectral density (PSD) and spatial frequency such that PSD $\propto f^{-\beta}$. The slope of the power spectral density plotted as a function of $f$ in $\log$ space is the spectral (or scaling) exponent, $\beta$. To test for scale invariance in the $\mathrm{S}_{\mathrm{H} \max }$ orientations, the rotation of each individual stress measurement from the mean direction for that well was analyzed using two different approaches. 

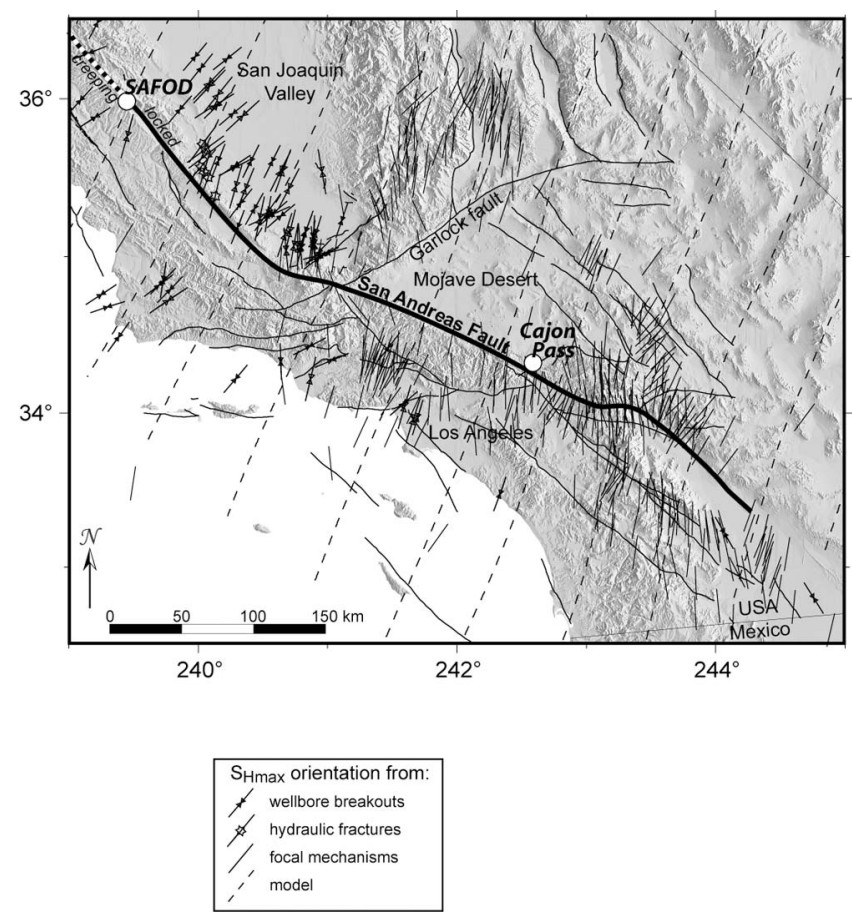

Figure 1. Stress map of central and southern California [after Townend and Zoback, 2004] showing locations of the two study wells. The direction of the maximum horizontal compressive stress $\left(\mathrm{S}_{\mathrm{Hmax}}\right.$, short straight lines) is derived from multiple independent stress indicators (plain: earthquake focal mechanisms; arrows: wellbore breakouts; stars: hydraulic fractures). There is a generally consistent northeast-southwest $\mathrm{S}_{\mathrm{Hmax}}$ orientation in this area, in agreement with tectonic modelling (long dashed lines after Flesch et al. [2000]), but with local variations. At SAFOD, the San Andreas Fault (thick line) changes behaviour from creeping (dashed) to locked (solid) [Wyss et al., 2004; Murray and Segall, 2005].

The first approach employed in our study was a Fourierbased spectral analysis approach which provides information on the amount of variation seen over wavelengths ranging from twice the sample spacing to the length of the entire data set. A limitation of a periodogram approach such as this, however, is that the analyzed data series must be continuous, whereas the wellbore failure data contain intervals without observations due to either missing/poor image data or local regions where the stress concentration around the borehole did not exceed the strength of the rock. For this reason, data had to be interpolated over gaps before performing the periodogram analysis.

[6] To overcome the limitations of the periodogram approach, we present below results of an analysis using an auto-regressive (AR) spectral analysis method designed specifically for data with intervals of missing observations (ARMASA, by Broersen et al. [2004]). ARMASA is a moving average spectral analysis method that first creates hundreds of AR (auto-regressive), MA (moving-average), and ARMA models based on the data. Using automatic statistical model selection criteria, it determines the best model from each category and then calculates the power spectrum of the one that has the smallest expected prediction error. Bos et al. [2002] modified the approach to analyze segmented data sets, and de Waele [2003] further modified it to analyze data sets with missing observations. The latter is an approximate, finite-interval maximum likelihood estimator that works exceptionally well even when more than $90 \%$ of the observations are missing [Broersen et al., 2004]. Codes for the basic ARMASA approaches can be downloaded from the MATLAB ${ }^{\mathrm{TM}}$ Central File Exchange (www. mathworks.com).

[7] This method has the advantage that no assumptions need to be made about absent data. The techniques utilized in this study are discussed in more detail by Day-Lewis [2007].

\section{Results}

[8] Both spectral analysis methods reveal fractal-like variations in PSD of stress orientation variations with spatial frequency in the study wells. The PSD drops off linearly in $\log -\log$ space with increasing frequency, revealing that the variations in stress orientation are indeed self-similar (Figure 2). The spectral exponents $(\beta)$ obtained using the AR method yielded $\beta=1.47$ for the SAFOD Pilot Hole and $\beta=$ 1.12 for Cajon Pass (Figure 3 and Table 1). This indicates that the data series behave as power-law noise processes between 1 -over- $f$ noise ( $\beta=1$, sometimes called pink noise), which has been observed in numerous dynamic systems and natural phenomena [Bak et al., 1987], and Brownian motion $(\beta=2$, or a random walk). 1-over- $f$ noise behaviour $(\beta=1)$ is characteristic of heterogeneity in physical properties measured by geophysical wireline logging (e.g., sonic velocity, formation density and resistivity, etc.) in a variety of locations and tectonic environments, including Cajon Pass [Dolan and Bean, 1997; Leary, 1997; Leonardi and Kümpel, 1998]. Spectral analyses of depth-dependent variations in several physical property logs (P-wave velocity, electrical resistivity, natural gamma radiation, and formation density) from the SAFOD Pilot Hole also yield $\beta \approx 1$ for these $\operatorname{logs}(\beta=0.96$ to 1.15 [see Day-Lewis, 2007]). The spectral exponents for physical property heterogeneity in both study wells are therefore similar, but lower than the spectral exponents found for the stress heterogeneity. It is therefore apparent that something other than physical property changes is responsible for the observed stress variability.

\section{Discussion}

[9] Shear failure on a fracture intersecting a well will affect the wellbore stress concentration, perturbing both the magnitude and the orientation of the wellbore stresses (and, hence, the orientation of wellbore failure) for distances along the well that are dependent on the size of the slipping plane [e.g., Shamir and Zoback, 1992]. Hickman and Zoback [2004] argue that the a pronounced breakout rotation at the bottom of the SAFOD Pilot Hole can be explained by slip on a fault seen on the image log at $2126 \mathrm{~m}$ depth. Fractures and faults are also known to have scale-invariant spatial and length distributions [Barton and La Pointe, 1995], as has been illustrated at Cajon Pass [Barton and Zoback, 1992; Leary, 1991]. Thus, borehole stress perturbations due to fault slip in a critically stressed crust might be expected to show similar scaling relationships. 


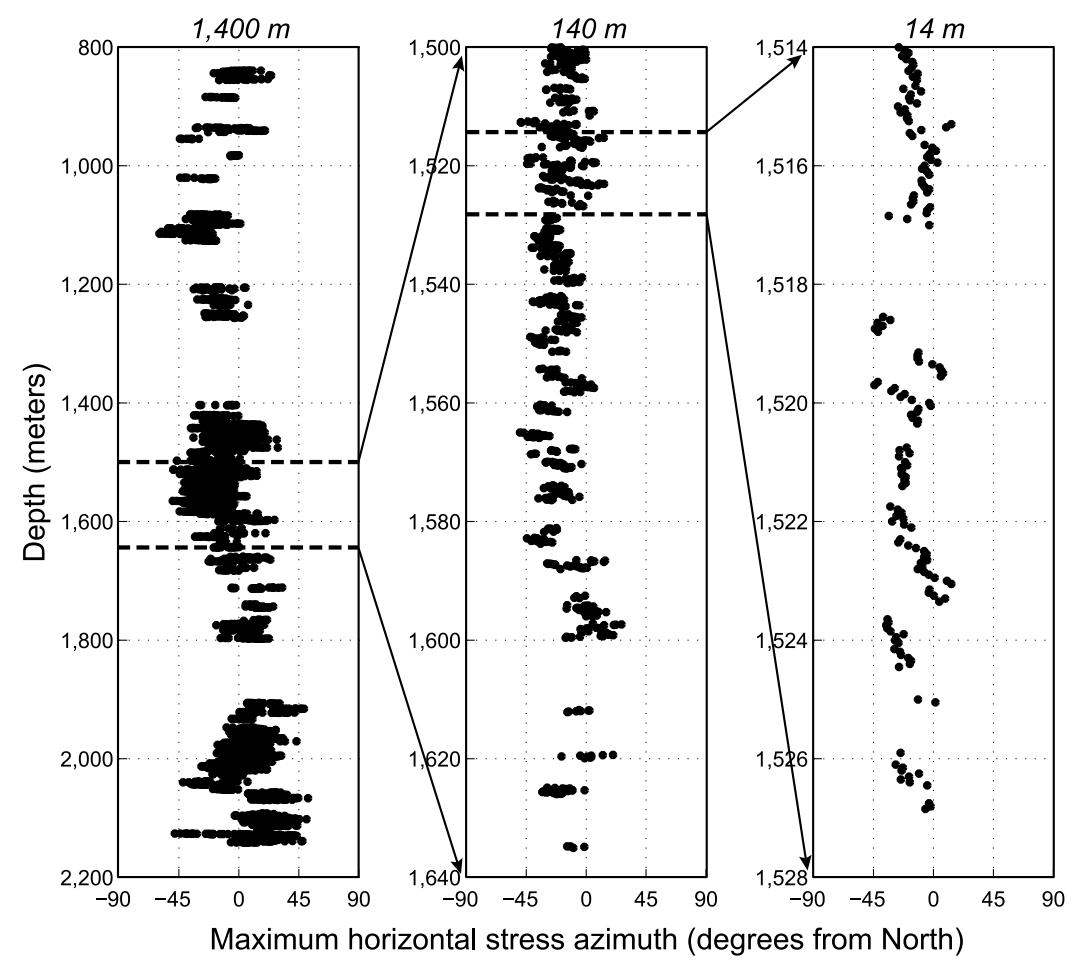

Figure 2. Detailed $\mathrm{S}_{\mathrm{Hmax}}$ azimuth measurements in the SAFOD Pilot Hole, sampled at $5 \mathrm{~cm}$ depth intervals in highresolution wellbore image logs [Hickman and Zoback, 2004]. Rotations in $\mathrm{S}_{\mathrm{Hmax}}$ azimuth occur at many wavelengths, and the general character of the rotations persists with increasing magnification (left to right). Gaps in the data represent intervals of missing or poor data and ambiguous or absent wellbore failure.

[10] Earthquakes display scale-invariant characteristics in magnitude, frequency of occurrence, and spatial distribution [Kanamori and Anderson, 1975]. By combining the Gutenberg-Richter empirical relation between the number of earthquakes and their magnitude with laws that relate magnitude to seismic moment and moment to fault size, the number of earthquakes, $\mathrm{N}$, can be expressed as a function of fault size, $\mathrm{L}$, according to:

$$
\log \mathrm{N} \propto-(\mathrm{bd} / \mathrm{q}) \log \mathrm{L}, \text { or } \mathrm{N} \propto \mathrm{L}^{-\mathrm{D}}
$$

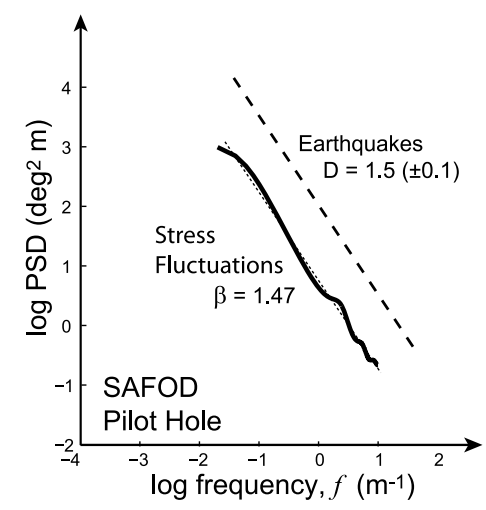

where $\mathrm{D}=\mathrm{bd} / \mathrm{q}$. We can therefore think of $\mathrm{D}$ as a scaling exponent, analogous to the spectral exponent $\beta$ defined above for stress variations. Both $\mathrm{d}$ and $\mathrm{q}$ are constants that depend on the geometry of the fault. The parameter $b$ is the well-known earthquake "b-value" that describes the relative numbers of small versus large events. While $\mathrm{b} \approx 1$ and $\mathrm{q} \approx 1.5$ worldwide [Kanamori and Anderson, 1975], locally higher or lower $\mathrm{b}$-values are common and may depend on regional stress levels, fault strength, faulting style, or the spatial distribution of seismicity [Huang and Turcotte, 1988; Schorlemmer et al.,

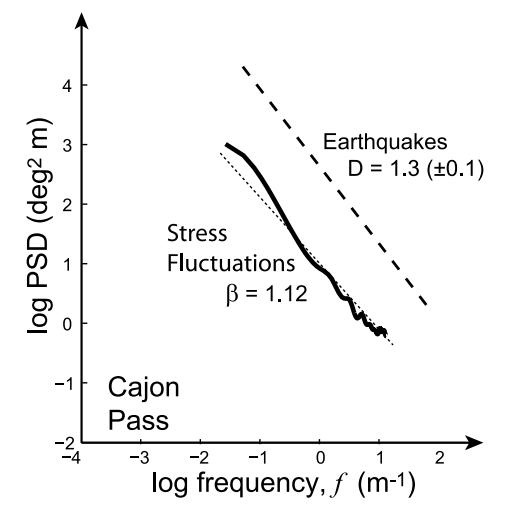

Figure 3. Power spectra for the variation in $\mathrm{S}_{\mathrm{Hmax}}$ orientation in the SAFOD Pilot Hole and Cajon Pass well determined using an auto-regressive spectral analysis. The results reveal a power-law relationship between power spectral density (PSD) and spatial frequency (f), indicating scale-invariance. The slopes of the spectra are very close to the scaling parameters, D, derived in the text to relate the number of earthquakes to fault size at both locations. The position of the dashed line is arbitrary - only the slope of the line is relevant. The dotted line shows the $\beta$ slope derived from the fit to the AR data. The small differences in earthquake scaling behaviour between the two locations (reflected in their respective $b$ values) appears to be reflected by similar differences in the stress heterogeneity scaling. 
Table 1. Spectral Analysis Results and Earthquake Parameters

\begin{tabular}{lccc}
\hline \multicolumn{1}{c}{ Borehole } & AR $\beta$ & D & b-value \\
\hline SAFOD Pilot Hole & $1.470( \pm 0.014)$ & 1.5 & 1.1 \\
Cajon Pass & $1.125( \pm 0.018)$ & 1.3 & 0.9 \\
Siljan & 1.74 & $1.35-2.0$ & $1.04-1.35$ \\
KTB-VB & 1.71 & $>1.3-1.5$ & $\sim 1$ \\
KTB-HB & 1.82 & $>1.3-1.5$ & $\sim 1$ \\
\hline
\end{tabular}

2005; Steacy et al., 1996]. The parameter d ranges from 2 or small, radially-symmetric ruptures to 3 for larger events that span the brittle crust [King, 1983]. Near the San Andreas Fault in Parkfield, $\mathrm{d} / \mathrm{q}$ is around 1.5 but may be as low as 1.3, and $\mathrm{b} \approx 1.1$ [Wyss et al., 2004], yielding $\mathrm{D}=1.5 \pm 0.1$. By contrast, at Cajon Pass $\mathrm{b} \approx 0.9$ [Schorlemmer et al., 2004; Wesnousky, 1994], and using a similar range of values for $\mathrm{d} / \mathrm{q}$, $\mathrm{D}=1.3 \pm 0.1$.

[11] The earthquake scaling exponents (D) derived above for the two study wells are similar to the spectral exponents we obtain for stress orientation heterogeneity (Table 1 and Figure 3). That is, the number of earthquakes in the crust near the San Andreas fault drops off with increasing fault size at a similar rate that stress orientation heterogeneity increases with distance along the well. This suggests that the fractal size distribution of seismogenic shear faults in the crust surrounding the study sites controls the multi-scale wellbore stress rotations observed. In other words, the overall pattern of wellbore stress variations along the wells results from the superposition of small stress perturbations from numerous small faults and larger, long-wavelength perturbations caused by fewer larger faults. In particular, at the SAFOD Pilot Hole, both $\beta$ and $\mathrm{D}$ are higher than at Cajon Pass, suggesting from equation (1) the occurrence of more frequent small earthquakes in the crust near SAFOD. The SAFOD Pilot Hole is located at the southern end of a creeping segment of the San Andreas fault characterized by numerous small earthquakes and aseismic creep of the order of 35 to $50 \mathrm{~mm}$ per year [Murray and Segall, 2005]. Near Cajon Pass, on the other hand, the San Andreas Fault is locked; Cajon Pass itself is close to the southernmost extent of the last great earthquake rupture on that part of the fault, a magnitude 7.9 in 1857. The correspondence between stress scaling and the local behaviour of the San Andreas suggests that stress heterogeneity in the crust near this major fault is representative of the mechanics of fault loading and spatial variations in stresses and/or strength along the fault itself.

[12] Day-Lewis [2007] also computed power spectra for two sites where deep boreholes have been drilled in intraplate regions. Breakout observations from the Siljan well, Sweden [Lund and Zoback, 1999] and the KTB Pilot Hole (VB) and Main Borehole (HB) in Germany [Brudy et al., 1997]. Table 1 shows that the $\beta$ values in these wells as well as the b- and D-values determined for the Siljan and KTB sites. Note that while the $\mathrm{b}$ - and D-values for the intraplate sites are similar to the Cajon Pass and SAFOD sites, the $\beta$ values for both Siljan and KTB are considerably higher than either the Cajon Pass or SAFOD pilot hole. This indicates that there are a proportionally greater number of long-wavelength stress variations than in the boreholes near the San Andreas. The overall spectral density of the fluctuations of stress orientation with depth in the intraplate boreholes are slightly less than the two boreholes along the
San Andreas, indicating less variability in stress orientation with depth. This appears to be consistent with the observation that the rate of seismicity in these intraplate settings is lower than along the San Andreas Fault. The b-value for the KTB site is unpublished, from written correspondence, S. Shapiro.

\section{Conclusions}

[13] Our investigation reveals scale-invariant in-situ stress fluctuations over length scales from tens of $\mathrm{cm}$ to several $\mathrm{km}$, a similar range over which faults and fault systems are believed to control the occurrence of earthquakes. The apparent difference in stress scaling parameters between the two study wells corresponds to differences in the earthquake magnitude-frequency statistics for each site, suggesting that stress heterogeneity adjacent to active faults like the San Andreas is due to local faulting. Our conclusions are consistent with the concepts of fractal fault distributions and a scale-free, complex network of seismicity in a critically stressed brittle crust [Turcotte and Malamud, 2002].

[14] The correspondence between the amount of stress heterogeneity and local fault behaviour may prove useful in models of dynamic earthquake rupture, where many of the key parameters including stress and fault strength appear to vary spatially [e.g., Aagaard and Heaton, 2008]. These findings may also have implications for the role of heterogeneous fault loading conditions in earthquake propagation on different fault segments [Harris, 2004].

[15] Acknowledgments. The authors thank Gadi Shamir (Ministry of National Infrastructures, Israel) for providing data and Brad Aagaard and Art McGarr of the U.S. Geological Survey for their comments on the manuscript. This work was supported by the National Science Foundation Earthscope Program, the Stanford Rock and Borehole Geophysics Project, and the U.S. Geological Survey's Earthquake Hazards Program. A.D.L. appreciates support from the Society of Exploration Geophysicists Foundation and the Society of Professional Well Log Analysts.

\section{References}

Aagaard, B. T., and T. H. Heaton (2008), Constraining fault constitutive behavior with slip and stress heterogeneity, J. Geophys. Res., 113, B04301, doi:10.1029/2006JB004793.

Bak, P., C. Tang, and K. Wiesenfeld (1987), Self-organized criticality: An explanation for 1/f noise, Phys. Rev. Lett., 59, 381-384, doi:10.1103/ PhysRevLett.59.381.

Barton, C. C., and P. R. La Pointe (Eds.) (1995), Fractals in the Earth Sciences, Plenum, New York.

Barton, C. A., and M. D. Zoback (1992), Self-similar distribution and properties of macroscopic fractures at depth in crystalline rock in the Cajon Pass Scientific Drill Hole, J. Geophys. Res., 97, 5181-5200, doi:10.1029/91JB01674.

Barton, C. A., and M. D. Zoback (1994), Stress perturbations associated with active faults penetrated by boreholes: Evidence for near complete stress drop and a new technique for stress magnitude measurement, J. Geophys. Res., 99, 9373-9390, doi:10.1029/93JB03359.

Bell, J. S., and D. I. Gough (1979), Northeast-southwest compressive stress in Alberta: Evidence from oil wells, Earth Planet. Sci. Lett., 45, 475-482, doi:10.1016/0012-821X(79)90146-8.

Boness, N. L., and M. D. Zoback (2006), A multi-scale study of the mechanisms controlling shear velocity anisotropy in the San Andreas fault Observatory at Depth, Geophysics, 71, F131-F146, doi:10.1190/1.2231107.

Bos, R., S. de Waele, and P. M. T. Broersen (2002), Autoregressive spectral estimation by application of the Burg algorithm to irregularly sampled data, IEEE Trans. Instrum. Meas., 51, 1289-1294, doi:10.1109/ TIM.2002.808031.

Broersen, P. M. T., S. de Waele, and R. Bos (2004), Application of autoregressive spectral analysis to missing data problems, IEEE Trans. Instrum. Meas., 53, 981-986, doi:10.1109/TIM.2004.830597. 
Brudy, M., M. D. Zoback, K. Fuchs, F. Rummel, and J. Baumgartner (1997), Estimation of the complete stress tensor to $8 \mathrm{~km}$ depth in the KTB scientific drill holes: Implications for crustal strength, J. Geophys. Res., 102, 18,453-18,475, doi:10.1029/96JB02942.

Day-Lewis, A. D. F. (2007), Characterization and modelling of in situ stress heterogeneity, Ph.D. thesis, 121 pp., Stanford Univ., Stanford, Calif. (Available at http://srb.stanford.edu/resources.theses.php)

de Waele, S. (2003), Automatic inference from finite time observations of stationary stochastic signals, Ph.D. thesis, 205 pp., Tech. Univ., Delft, Netherlands, 13 May.

Dolan, S. S., and C. J. Bean (1997), Some remarks on the estimation of fractal scaling parameters from borehole wire-line logs, Geophys. Res. Lett., 24, 1271-1274, doi:10.1029/97GL00987.

Flesch, L. M., W. E. Holt, A. J. Haines, and B. Shen-Tu (2000), Dynamics of the Pacific-North American plate boundary in the western United States, Science, 287, 834-836, doi:10.1126/science.287.5454.834.

Harris, R. A. (2004), Numerical simulations of large earthquakes: Dynamic rupture propagation on heterogeneous faults, Pure Appl. Geophys., 161, 2171-2181, doi:10.1007/s00024-004-2556-8.

Hickman, S., and M. Zoback (2004), Stress orientations and magnitudes in the SAFOD Pilot Hole: Implications for the strength of the San Andreas fault at Parkfield, Geophys. Res. Lett., 31, L15S12, doi:10.1029/ 2004GL020043.

Huang, J., and D. L. Turcotte (1988), Fractal distributions of stress and strength and variations of b-value, Earth Planet. Sci. Lett., 91, 223-230, doi:10.1016/0012-821X(88)90164-1.

Kanamori, H., and D. L. Anderson (1975), Theoretical basis of some empirical relations in seismology, Bull. Seismol. Soc. Am., 65, 1073-1095.

King, G. C. P. (1983), The accommodation of large strains in the upper lithosphere of the Earth and other solids by self-similar fault systems: The geometrical origin of b-value, Pure Appl. Geophys., 121, 761-815, doi:10.1007/BF02590182.

Leary, P. (1991), Deep borehole evidence for fractal distribution of fractures in crystalline rock, Geophys. J. Int., 107, 615-627, doi:10.1111/ j.1365-246X.1991.tb01421.x.

Leary, P. C. (1997), Rock as a critical-point system and the inherent implausibility of reliable earthquake prediction, Geophys. J. Int., 131, 451-466, doi:10.1111/j.1365-246X.1997.tb06589.x.

Leonardi, S., and H.-J. Kümpel (1998), Variability of geophysical log data and the signature of crustal heterogeneities at the KTB, Geophys. J. Int. 135, 964-974, doi:10.1046/j.1365-246X.1998.00714.x.
Lund, B., and M. D. Zoback (1999), Orientation and magnitude of in situ stress to $6.5 \mathrm{~km}$ depth in the Baltic Shield, Int. J. Rock Mech. Min. Sci. 36, 169-190, doi:10.1016/S0148-9062(98)00183-1.

Murray, J. R., and P. Segall (2005), Spatiotemporal evolution of a transient slip event on the San Andreas fault near Parkfield, California, J. Geophys. Res., 110, B09407, doi:10.1029/2005JB003651.

Schorlemmer, D., S. Wiemer, and M. Wyss (2004), Earthquake statistics at Parkfield: 1. Stationarity of b values, J. Geophys. Res., 109, B12307, doi:10.1029/2004JB003234.

Schorlemmer, D., S. Wiemer, and M. Wyss (2005), Variations in earthquake-size distribution across different stress regimes, Nature, 437, 539-542, doi:10.1038/nature04094.

Shamir, G., and M. D. Zoback (1992), Stress orientation profile to $3.5 \mathrm{~km}$ near the San Andreas fault at Cajon Pass, California, J. Geophys. Res., 97, 5059-5080, doi:10.1029/91JB02959.

Steacy, S. J., J. McCloskey, C. J. Bean, and J. Ren (1996), Heterogeneity in a self-organised critical earthquake model, Geophys. Res. Lett., 23, 383-386, doi:10.1029/96GL00257.

Townend, J., and M. D. Zoback (2004), Regional tectonic stress near the San Andreas fault in central and southern California, Geophys. Res. Lett., 31, L15S11, doi:10.1029/2003GL018918.

Turcotte, D. L., and B. D. Malamud (2002), Earthquakes as a complex system, in International Handbook of Earthquake and Engineering Seismology, edited by W. Lee et al., pp. 209-227, doi:10.1016/ S0074-6142(02)80217-0, Academic, London.

Wesnousky, S. G. (1994), The Gutenberg-Richter or characteristic earthquake distribution, which is it?, Bull. Seismol. Soc. Am., 84, 1940-1959.

Wyss, M., C. G. Sammis, R. M. Nadeau, and S. Wiemer (2004), Fractal dimension and $\mathrm{b}$-value on creeping and locked patches of the San Andreas fault near Parkfield, California, Bull. Seismol. Soc. Am., 94, 410-421, doi:10.1785/0120030054.

Zoback, M. D., D. Moos, L. Mastin, and R. N. Anderson (1985), Wellbore breakouts and in situ stress, J. Geophys. Res., 90, 5523-5530, doi:10.1029/JB090iB07p05523.

Zoback, M. L., et al. (1989), Global patterns of tectonic stress, Nature, 341, 291-298, doi:10.1038/341291a0.

A. Day-Lewis and M. Zoback, Department of Geophysics, Stanford University, Mitchell Building, 397 Panama Mall, Stanford, CA 953052214, USA. (zoback@stanford.edu)

S. Hickman, U.S. Geological Survey, MS 977, 345 Middlefield Rd., Menlo Park, CA 94025, USA. 